\title{
PENGARUH STRATEGI PEMBELAJARAN RECIPROCAL TEACHING TERHADAP KEMAMPUAN BERPIKIR KRITIS BIOLOGI SISWA SMA ISLAM AL - MA'ARIF SINGOSARI MALANG
}

\section{THE INFLUENCE OF RECIPROCAL TEACHING STRATEGY) TOWARDS CRITICAL THINKING OF BIOLOGY CONCEPT OF STUDENTS OF SMAI AL-MA'ARIF SINGOSARI MALANG}

\author{
Dwi Candra Setiawan ${ }^{1}$, A. D. Corebima' ${ }^{2,}$ Siti Zubaidah ${ }^{2}$ \\ ${ }^{1}$ Staf Pengajar Pendidikan Biologi, IKIP Budi Utomo, Malang \\ e-mail: dwicandra14@gmail.com
}

\begin{abstract}
The objectives of this research were to explain the influence of RT strategy towards critical thinking. Quasi-expermental with Pretest-Postest Nonequivalent Control Group Design was used in this research. The independent variable was teaching strategy (reciprocal teaching). The dependent variable was metacognitive competence, critical thinking, and the understanding of concept. The population of this research was all of the students of grade X of SMAI Al Ma'arif singosari, Malang. The sample of this research was the students of grade X-1 as an experimental group and the students of X-4 as a control group. Critical thinking was measured by an essay test. The validity and the reliability of the instruments were firstly tested. The data were taken in pretest-posttest. Anakova was used in the hypothesis test with the significance level $0.05(\mathrm{P}<0.05)$. The results of this research showed that teaching strategies influenced critical thinking. Regarding with the potential of RT, it is suggested that this strategy could be implemented so that students' competencies, besides cognitive domain, could be empowered
\end{abstract}

Key words: Reciprocal Teaching, critical thinking

\begin{abstract}
ABSTRAK. Tujuan penelitian ini ialah menjelaskan pengaruh strategi RT terhadap kemampuan berpikir kritis. Rancangan penelitian yang digunakan ialah quasi eksperimen dengan Pretest-Postest Nonequivalent Control Group Design. Variabel bebas adalah strategi pembelajaran (reciprocal teaching). Variabel terikat adalah kemampuan berpikir kritis Populasi penelitian ialah seluruh siswa kelas X SMAI Al Ma'Arif Singosari Malang. Sampel penelitian adalah siswa kelas X-1 sebagai kelas eksperimen dan X-4 sebagai kelas kontrol. Kemampuan berpikir kritis diukur menggunakan rubric berpikir kritis dan rubrik berpikir kritis. Instrumen tes terlebih dahulu diuji validitas dan reliabilitas. Data diambil pada saat pretes, postes. Uji hipotesis menggunakan anakova dengan taraf signifikansi 0,05 $(\mathrm{P}<0,05)$. Hasil penelitian menunjukkan strategi pembelajaran berpengaruh terhadap kemampuan berpikir kritis siswa, Melihat potensi dari RT tersebut disarankan agar dalam pembelajaran strategi ini dapat diaplikasikan, sehingga kemampuan siswa selain kognitif dapat diberdayakan.
\end{abstract}

Kata kunci: Resiprocal Teaching, berpikir kritis

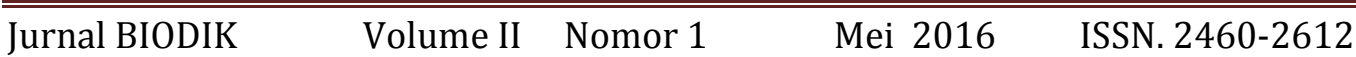




\section{PENDAHULUAN}

Pendidikan merupakan salah satu aspek yang sangat penting dalam mendukung kemajuan bangsa di masa depan. Oleh karena itu dunia pendidikan haruslah selalu ditingkatkan setiap waktu. Hal ini juga berlaku pada pendidikan di Indonesia. Pendidikan di Indonesia pada saat ini masih sangat perlu ditingkatkan lagi. Banyak cara atau metode dalam meningkatkan serta memperbaiki pendidikan di Indonesia, baik dari segi mutu maupun kualitasnya. Perbaikan sistem pendidikan saat ini harus memperhatikan beberapa prinsip dari pendidikan yang ada, seperti salah satu prinsip yang penting dari pendidikan saat ini adalah pembelajaran yang melibatkan siswa secara aktif, sehingga proses belajar mengajar tidak lagi berpusat pada guru (teacher-centered) akan tetapi berpusat pada siswa (studentcentered). Pembelajaran saat ini, baik strategi maupun materi terus-menerus diperbaiki, terutama dalam pemberdayaan kemampuan metakognitif dan berpikir kritis siswa terhadap biologi. Tapi kenyaataannya pendidikan di Indonesia pada saat ini masih menitik beratkan pada kemampuan kognitif siswa saja, sedangkan menurut Permen Diknas RI No. 22 Th 2006 disebutkan bahwa mata pelajaran Biologi di SMA dikembangkan melalui kemampuan berpikir analisis, induktif, dan deduktif untuk menyelesaikan masalah yang berkaitan dengan peristiwa alam sekitar. Metakognitif dan Berpikir Kritis terhadap materi Biologi merupakan tujuan yang akan dicapai dalam pembelajaran Biologi. Terkait dengan tujuan tersebut seharusnya pembelajaran biologi menitik beratkan pada pengembangan kemampuan berpikir kritis siswa siswa.

Menurut Zubaidah (2007) berpikir kritis ialah berpikir memecahkan masalah dengan sifat dan bakat kritis yakni sifat ingin rasa ingin tahu, berani mengambil resiko, dan sifat selalu menghargai hak-hak orang lain. Berdasarkan pengertian tersebut dapat mengetahui kemampuan berpikir siswa dengan menggunakan indikator dari komponen-komponen berikut yaitu merumuskan masalah, memberikan argument, melakukan deduksi, melakukan induksi, melakukan evaluasi dan memutuskan (Ennis, 1985 dan Marzano et al., 1988 dalam Arnyana, 2004)

Berdasarkan hasil observasi yang dilakukan pada sekolah SMAI Al-Maarif Singosari, menunjukkan bahwa pada proses pembelajaran masih banyak terpusat pada guru, disamping itu dalam hal pemberdayaan kemampuan berpikir kritis belum dioptimalkan. Hal yang lebih diprioritaskan adalah hasil belajar kognitif saja, sehingga hal ini perlu diperbaiki lagi untuk memberdayakan siswa SMAI AlMa'arif Singosari terhadap kemampuan berpikir kritis. Menurut Wahidin (1996) ada beberapa keuntungan yang diperoleh dari pembelajaran yang menekankan pada proses keterampilan berpikir kritis, yaitu: 1) belajar lebih ekonomis, yakni bahwa apa yang diperoleh dari pengajarannya akan tahan lama dalam pikiran siswa; 2) cenderung menambah semangat belajar, gairah (antusias) baik pada guru maupun pada siswa; 3) diharapkan siswa dapat memiliki sikap ilmiah; 4) siswa memiliki kemampuan memecahkan masalah baik pada saat proses belajar mengajar di kelas maupun dalam menghadapi permasalahan nyata yang akan dialaminya.

Strategi yang dirasa dapat memberdayakan kemampuan di atas adalah RT (Reciprocal Teaching). Reciprocal teaching (RT) merupakan strategi pembelajaran konstruktivisme yang didasarkan pada prinsip-prinsip membuat pertanyaan, mengajar keterampilan metakognitif melalui pengajaran dan pemodelan guru untuk meningkatkan 
keterampilan membaca siswa (Slavin, 2006). Strategi ini mengandung kegiatan meringkas, menyusun pertanyaan, memprediksi dan mengklarifikasi. Kegiatan meringkas dapat melatih siswa mengelola informasi. Pada kegiatan ini diperlukan aktivitas membaca, dan merangkum ide. Khusus pada kegiatan menyusun pertanyaan akan merangsang siswa untuk berlatih berpikir kritis, karena pada kegiatan ini merupakan usaha untuk mengembangkan rasa ingin tahu siswa dalam memperoleh informasi. Selain itu pada tahap memprediksi dan mengklarifikasi dimana siswa menjawab pertanyaan akan memicu anak untuk berpikir, karena proses belajarnya tidak hanya berlangsung secara informatif saja (Corebima, 2008). Berdasarkan penjelasan di atas maka, Resiprocal teaching merupakan pembelajaran yang dirasa tepat untuk lebih memberdayakan kemampuan berpikir kritis. Hal ini dikarenakan dalam penerapan kedua strategi ini sangat mendukung dan saling melengkapi satu sama lain.

\section{METODE}

Jenis penelitian yang diterapkan
adalah eksperimen semu (quasi experiment). Desain penelitian yang digunakan adalah Pretest-Postest Nonequivalent Control Group Design (Beaumont, 2009).

Sampel dalam penelitian ini ialah siswa kelas X-1 dan X-4. Kelas X-1 sebagai kelas eksperimen dan kelas $\mathrm{X}-4$ sebagai kelas kontrol. Jumlah siswa kelas X-1 sebanyak 40 siswa dan kelas X-4 sebanyak 39 siswa. Penentuan sampel dilakukan dengan teknik random sampling yang didasarkan pada nilai rata-rata UN yang hampir sama.

Perangkat pembelajaran yang digunakan dalam penelitian ini adalah silabus, rencana pelaksanaan pembelajaran
(RPP), lembar siswa (LS RT). Instrumen yang digunakan untuk mengukur variabel terikat adalah menggunakan rubrik kemampuan berpikir kritis.

Data penelitian ini berupa data kuantitatif yaitu skor dari rubrik berpikir kritis dengan tes essay. Data hasil ini dikumpulkan melalui pretes dan postes yang dilakukan sebelum dan sesudah seluruh materi pada semester 1 tahun ajaran 2012-2013 dilaksanakan. Data hasil penelitian yang menyangkut pengaruh penerapan strategi pembelajaran RT terhadap kemampuan berpikir kritis siswa dianalisis menggunakan analisis statistik kovarian (ANAKOVA).

\section{HASIL PENELITIAN DAN PEMBAHASAN}

Sebelum uji hipotesis dilakukan, uji Levene diterapkan untuk mengetahui distribusi data. Hasil uji Levene menunjukkan kemampuan berpikir kritis berdasarkan analisis, diketahui signifikansi $(0.244)>0.05$ jadi data terdistribusi normal. Sedangkan untuk homogenitas berdasarkan hasil analisis menujukkan nilai signifikansi $(0.211)>0.05$ sehingga dapat disimpulkan bahwa data diambil dari sampel yang homogen. Untuk uji hipotesis dapat dilihat pada tabel ringkasan anakova berikut. 


\section{a. Uji Hipotesis Kemampuan Metakognitif Inventori MAI}

Tabel Ringkasan Anakova Hasil Penghitungan Data Kemampuan Berpikir Kritis

\begin{tabular}{lrrrrr}
\hline Source & $\begin{array}{c}\text { Type III Sum of } \\
\text { Squares }\end{array}$ & Df & Mean Square & \multicolumn{1}{c}{ F } & \multicolumn{1}{c}{ Sig. } \\
\hline Corrected Model & $3926.305^{\mathrm{a}}$ & 2 & 1963.152 & 42.624 & .000 \\
Intercept & 40.819 & 1 & 40.819 & .886 & .350 \\
Y & 1730.868 & 1 & 1730.868 & 37.581 & .000 \\
X & 3477.562 & 1 & 3477.562 & 75.505 & .000 \\
Error & 3270.074 & 71 & 46.057 & & \\
Total & 44524.000 & 74 & & &
\end{tabular}

Berdasarkan hasil analisis SPSS di atas, diketahui bahwa nilai signifikansi $(0,0)<0,05$, sehingga hipotesis nol ditolak dan hipotesis penelitian diterima. Disimpulkan bahwa RT berpengaruh secara signifikan terhadap kemampuan berpikir kritis siswa. Hasil ini dikarenakan RT merupakan strategi yang di dalam pelaksanaan terdapat empat tahapan yaitu meringkas, menyusun pertanyaaan, memprediksi dan mengklarifikasi yang mampu meningkatkan kemampuan berpikir kritis siswa. Pada tahap proses meringkas, siswa akan berupaya untuk membuat suatu rencana dengan cara mengumpulkan berbagai informasi penting berkaitan dengan konsep yang akan dipelajari untuk dijadikan rangkuman, yang akan disampaikan kepada rekannya dan dikaji lebih lanjut. Pada tahap meringkas siswa akan mampu memantau dan mengevaluasi sejauh mana kemampuannya dalam memahami konsep melalui ringkasan yang telah dibuatnya. Hal ini sejalan dengan pendapat Pierce (2004) yang menyebutkan bahwa menulis ringkasan bukan hanya meningkatkan pemahaman siswa, tetapi juga membantu siswa untuk memonitor pemahamannya, sehingga dengan demikian juga akan melatih siswa untuk berpikir kritis. Selanjutnya tahap mengklarifikasi, siswa diberikan kesempatan untuk menyampaikan pendapat kepada sesama teman sehingga siswa tidak hanya berpikir dengan kemampuannya sendiri tetapi berdiskusi dengan sesama teman untuk mencari pemecahan masalah yang terbaik. Selain itu siswa yang memiliki kemampuan rendah akan terbantu dengan siswa yang memiliki kemampuan akademik yang lebih tinggi melalui proses diskusi.

Pendapat di atas juga diperkuat oleh Palincar \& Brown,A (1984) yang mengatakan bahwa model pembelajaran reciprocal teaching cukup efektif digunakan untuk membantu siswa memahami bacaan. Adanya pemahaman siswa yang lebih terhadap suatu materi atau masalah yang dihadapi akan mampu memberdayakan kemampuan berpikir kritis siswa, terlebih aspek indikator berpikir kritis seperti mampu memberikan argument yang sesuai dengan alasan, memberikan interpretasi terhadap suatu masalah, melakukan investigasi dan memberikan alternativealternatif penyelesaian.

Strategi RT juga mampu memberdayakan kemampuan berpikir kritis siswa dikarenakan RT merupakan salah satu pembelajaran konstruktivis, dimana pemebelajaran ini menekankan pada aktivitas siswa sehingga dapat membantu memberdayakan kemampuan berpikir kritis siswa. Pembelajaran perubahan konseptual yang mendasarkan diri pada paham konstruktivisme, sesungguhnya adalah pembelajaran yang berbasis keterampilan berpikir. Pembelajaran perubahan konseptual memfasilitasi siswa untuk berpartisipasi aktif mengkonstruksi pengetahuannya. Dalam proses tersebut, siswa dapat menguji dan mereview ide-idenya berdasarkan pengetahuan awal yang telah dimiliki, menerapkannya dalam situasi yang baru, dan mengintegrasikan 
pengetahuan tersebut ke struktur kognitif yang dimiliki. Proses ini, menurut Berns \& Erickson (2001) adalah proses berpikir tingkat tinggi. Model pembelajaran perubahan konseptual menggunakan pertanyaan-pertanyaan konseptual yang memerlukan reasoning dan penyelidikan lebih lanjut.

Strategi RT merupakan salah satu pembelajaran kooperatif. Pembelajaran kooperatif merupakan pembelajaran yang menekankan pada interaksi sosial anak, pembelajaran kooperatif membantu siswa yang merasa kesulitan dalam memecahkan masalah akan terbantu dengan anak yang pintar dan memiliki kemampuan yang lebih tinggi dari anggota kelompoknya. Interaksi sosial yang terjadi dalam kelompok dapat meningkatkan kemampuan berpikir anak karena anak yang merasa kurang pandai akan terbantu dan anak yang merasa pandai akan beusaha menjelaskan kepada temannya yang kurang pandai sehingga pemahamannya menjadi lebih mendalam. Pendapat ini juga didukung oleh Green (dalam Corebima, 2008) yang menyatakan bahwa dalam pembelajaran kooperatif terjadi proses pembelajaran yang memungkinkan siswa dalam kelompoknya mengevaluasi kerja tiap anggota kelompok, memperbaiki interaksi sosial, juga adanya upaya memperbaiki penampilan tiap kelompok. Hal-hal ini akan mendorong perkembangan kemampuan metakognitif dan penguasaan kognitif siswa. Dalam suatu domain belajar, pemahaman (understanding) merupakan prasyarat mutlak untuk tingkatan kemampuan kognitif yang lebih tinggi, aplikasi, analisis, sintesis,dan evaluasi. Kemampuan-kemampuan kognitif yang berbasis pemahaman melibatkan kemampuan berpikir tingkat tinggi, seperti pemecahan masalah, berpikir kritis, kreatif, dan pengambilan keputusan (Berns \& Erickson, 2001). Jadi, pembelajaran untuk pemahaman identik dengan pembelajaran keterampilan berpikir salah satunya adalah kemampuan berpikir kritis siswa.

Berdasarkan uraian di atas diketahui bahwa RT mampu mengajak siswa untuk melatih mengkonstruk pemahaman dan juga mengungkapkan pendapat sehingga dapat mengasah kemampuan berpikirnya. Sehingga dengan penerapan RT dapat memberdayakan kemampuan berpikir kritis siswa.

\section{SIMPULAN}

Hasil penelitian menunjukkan strategi Reciprocal Teaching yang di dalamnya terdapat sintak-sintak seperti meringkas, membuat pertanyaan, memprediksi dan mengklarifikasi berpengaruh terhadap kemampuan berpikir kritis. Melihat potensi dari RT tersebut disarankan agar dalam pembelajaran strategi ini dapat diaplikasikan, sehingga kemampuan siswa selain kognitif dapat diberdayakan.

\section{DAFTAR RUJUKAN}

Berns, R. G., \& Erickson, P. M. (2001). Contextual teaching and learning: Preparing students for the new economy. Columbus, $\mathrm{OH}$ : National Dissemination Center for Career and Technical Education. (online) (www.cord.org/.../nccte_highlight05contextualtea.pdf). diakses tanggal 14 April 2013.

BSNP. 2006. Panduan Penyusunan Kurikulum Tingkat Satuan Pendidikan Jenjang Pendidikan Dasar dan Menengah. Jakarta: BSNP.

Corebima, A. D. 2008a. Guru Anak Bangsa. Makalah disajikan pada pelatihan pembelajaran Kooperatif TPS dan Jigsaw dengan strategi metakognitif pada guru-guru Biologi di SMAN Kota Pekanbaru. 5 Mei 2008.

Corebima, A. D. 2008b. Laporan Penelitian Payung di jurusan Biologi PPS UM. Lembaga Penelitian UM.

Corebima, A.D. 2008c. Review on: Learning strategies having bigger potency to empower thinking skill and concept gaining of lower academic students. Redesigning pedagogy international conference. December 2008.

Depdiknas. 2003. Konsep Pendidikan Berorientasi Kacakapan Hidup (Life Skill Education) Pendidikan Berbasis Luas (Broad-Base Education) Buku 1. 
Jakarta: Dirjen Pendidikan Dasar dan Menengah Direktorat Pendidikan Menengah Umum.

Doolittle, P. E., Hick, D. dan Triplett, C.F. 2006. Reciprocal Teaching for Reading Comprehension in Higher Education: A Strategy for Fostering The Deeper Understanding of Texts. International Journal of Teaching and Learning in Higher Education. 17 (2): 106-118. ISSN 1812-9129. Http://www. Isetl.org/ijtlhe/pdf/IJTLHE1.

Goodman, A. Tanpa tahun. Literacy tips: Reciprocal Teaching. (online) (www.asdk12.org/MiddleLink/LA/), diakses tanggal 3 Juni 2012.

Palincar, A\&Brown,A. 1984. Model Reciprocal Teaching of Comprehentionforestering and Comprehentionmonitoring Activities. Cognition and Instruction.

(online).(http://people.usac.ed/Palincsar reprocicalTeaching, diakses tanggal 10 Juli 2012.

Pierce, W. 2004. Metacognition: study strategies, monitoring, and motivation. A greatly expanded text version of workshop presented november 17 2004, at prince george's community college. (online)

(http://nsdl.org/resource/2200/20110312 195943843T), diakses tanggal $10 \mathrm{Juli}$ 2012.

Slavin, R. E. 2006. Educational Psychology Teory and Practise. New York: Pearson and Education. Inc.

Warouw, Z. W. M. 2009. Pengaruh Pembelajaran Metakognitif dengan Strategi Cooperative Script, dan Reciprocal Teaching pada Kemampuan Akademik Berbeda terhadap Kemampuan dan Keterampilan Metakognitif, Berpikir Kritis, Hasil Belajar Biologi Siswa serta Retensinya di SMP Negeri Manado. Disertasi tidak diterbitkan. Malang: Universitas Negeri Malang.

Zubaidah, S., Chaeruddin., Chasanah, U. 2007. Penerapan Metode Inquiri Dan Reciprocal Teaching untuk Meningkatkan Kemampuan Berpikir Siswa Kelas V MI Wahid Hasyim Malang. Laporan Penelitian Tindakan Kelas. 